\title{
Learning in the Era of Online Videos: How to Improve Teachers' Competencies of Producing Educational Videos
}

\author{
Guseva, Yulia and Kauppinen, Tomi.
}

Aalto University School of Science, Finland.

\begin{abstract}
Online videos have gained huge popularity among people seeking for entertainment, and increasingly also among learners. People seek for tips in videos, ranging widely from improving language skills to bike reparation, or from solving mathematical equations to indoor decoration. At the same time teachers are facing challenges of producing professional videos that can support learners to learn the variety of topics. Teachers at the higher education institutes are often professionals in presentation skills in classrooms, but can face challenges when presenting in videos. In this paper we present a process for improving skills needed to produce educational videos. The process starts from the assumption of often explicit question by the teacher: "How can I produce professional educational videos?" The process includes identifying main challenges teachers face, and continues with a series of hands-on workshops targeted to develop each of the skills followed by the video production itself. We report also an evaluation of the process with teachers from the Aalto University, discuss the implications and resulting categorization of production models.
\end{abstract}

Keywords: online learning; blended learning; video production; educational videos; community building; agile and lean methods. 


\section{Introduction}

In online and blended learning settings teachers provide examples, explain them by theories, and map theories to a bigger context. This comes in handy for settings like flipped classroom, where students are engaged with learning materials before the face-to-face sessions. Storytelling becomes vital to connect these learning elements together; and videos provide a natural way to tell stories. For this, it is also important to understand how students make use of the videos (see e.g. Seaton 2014). The goal is to engage and motivate the learner to feel the ownership of his or her own learning and associate himself or herself to the stories of the course. Making videos that carry the story to the learner requires key elements all the way from a good script and storyboard to acting in front of the camera or in some other way with sound and visuals. It is essential to support engagement of the learners (see Guo, Kim and Robin 2014, Lin et al., 2017) and take into account cognitive issues, for instance that learners learn from short videos (see Hsin and Cygas 2013) rather than from long ones.

However, as we have evidenced, teachers' abilities to produce engaging and learning supporting videos call for new ways of thinking. In this paper our contribution is to address this challenge by: i) a video production process for educational videos and ii) a set of workshops created in agile and lean fashion for teachers to obtain necessary skills and iii) community building around improving these video-making competences.

This paper is structured as follows. In section 2 we present emerging needs of teachers to prepare good quality videos and the corresponding challenges. In section 3 we present our approach to match these requirements. Section 4 discusses the community feedback, and the resulting categorization of video production types. In section 5 we provide concluding remarks.

\section{Understanding challenges in producing educational videos of good quality}

We have analyzed (with a permission) "first educational videos" made by teachers in our community within the Aalto Online Learning (A!OLE) ${ }^{1}$ project (Kauppinen and Malmi, 2017) at the Aalto University. As we have evidenced the main challenge has been that the resulting video is simply not engaging; however, this can be a result of several different reasons, each of them that can be tackled. We have categorized the challenges and issues into the following groups:

\footnotetext{
${ }^{1}$ See http://onlinelearning.aalto.fi/
} 
Presentation skills. We have evidenced stiff postures and monotonous intonations, wandering eyes, unclear articulation and anxiety while presenting. People are not used to presenting on camera; it is simply a new skill for them to obtain.

Content. Teachers usually try to apply either a traditional lecture format or scientific paper approach to the video making. As a consequence, there are plenty of videos that are overloaded with information - they are simply too long and hard to digest. Besides, teachers tend to ignore the planning of the video content "because they have given this lecture many times to a real audience”. As a result of this, videos are lacking a compelling structure, i.e. they are not straight to the point. Further on, in this setting it can also be troublesome for the post-production team to align visuals with the speech.

Visuals. The common issues on the visual side are text-heavy contents, poorly organized slides, a non-consistent slide design, lack of visuals and unauthorized image use. Visuals in the video need to be very clear since there is not much time to process them (about this see e.g. discussion about system 1- vs system 2- kind of thinking by Kahneman, 2011). Furthermore, many students nowadays watch videos on their mobile phones. This implies that if the slides are overloaded with textual information, it is simply not possible to follow them. Another challenge is "a boring talking head". If a teacher just talks out the information on slides, it hardly adds any value. A creative use of visuals can help to better support grasping the topic.

Video or audio quality. Due to budget and time constraints, people try to make videos on their own without professional help. Sometimes it can work out just fine, but if not, then certainly an obscure image or a hissing sound can be detrimental to the video.

Lack of understanding of the video production process. Every video production project has three stages: pre-production, production and post-production. It is essential to realise what happens at each stage and that actually most of the work happens outside of the video studio. Some teachers tend to underestimate the importance of pre-production and postproduction and the effects these stages have on the final video.

Since teachers generally run into the same problems and at the same time have a wish to produce good quality videos, we decided to implement an agile and lean improvement of video production skills via community building events. With this approach, teachers have a chance to go through a series of workshops and events to enhance their skills needed for video production. 


\section{Approach: agile improvement of video production skills via community building events}

A typical wish by a teacher wanting to support online learning is "I would like to have online videos where I explain essentials about the course topic to the students."

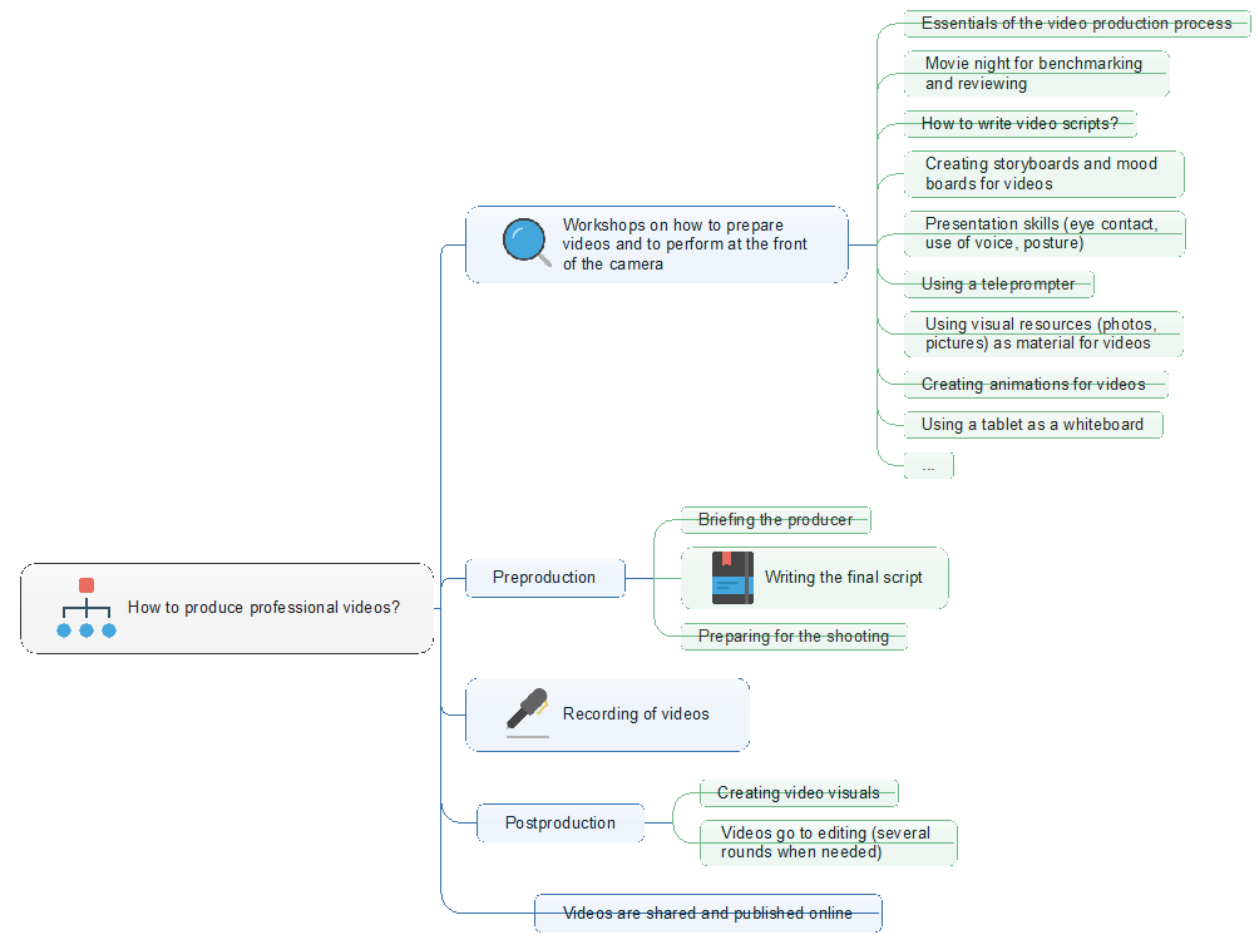

Figure 1. Process for engaging people to join the video producing community; getting improved videos as a result.

Now there are a range of professionals available to help teachers produce the videos, such as cameramen, sound recordists, gaffers or set designers. However, there is a crucial gap between the original wish by the teacher and being able to provide a brief to the producer on what exactly should be filmed. The gap is essentially to both plan what should be achieved with the video, i.e. how and what students should learn by watching it, and to help our teacher to get prepared for the production.

Our proposal to fill the gap is three-fold: 1) we request the teacher to join a number of workshops helping her or him to get prepared and to plan the video, 2) join the community 
of other educational video makers within the university and 3) we provide a brief for the producer to start the production of the video. Figure 1 depicts our process, ranging from workshops via pre-production to recording of the video, and to post-production and publishing of the video.

The goal of the hands-on workshops is to tackle the typical challenges teachers face, get essential skills needed in the video production and to learn by doing how to use certain tools. It is also vital to get tips from professionals, and exchange experiences and best practices.

Usually pilots in our Aalto Online Learning project have had six months to one year to achieve their goals. In the beginning of the project pilots are asked to go through three or four workshops that will help them in the pre-production stage. Examples of workshops are "Essentials of the video production process", "How to write video scripts" and "Benchmarking online courses". Then we move on to the production stage where we run workshops like "Developing presentation skills", "How to use a teleprompter" and "Using tablet as a white-board". For the post-production phase the workshops include "Using visual resources in your video" and "Creating animations for your videos".

Within the Aalto Online Learning project we have since May 2016 organized tens of these kinds of workshops related to video production. Here we provide a representative selection of these workshops to give an idea of their contents, activities and aimed deliverables.

Essentials of the video production process. "In this workshop we go through each stage of video production process and give tips to teachers regarding their upcoming video production. “

Movie night for benchmarking online courses. "Before you start making videos, it is good to know what is happening on the online course arena, familiarize oneself with best practices and also learn from bad examples. In this event we watch together and discuss different educational videos to get some ideas and inspiration for your own video production. “

How to write video scripts? "In the workshop participants are given tips on how to write a successful video script, what needs to be avoided and how to establish a more personal connection with the viewer. They can also get feedback on their own scripts.”

Developing presentation skills. "In this workshop participants train how to use gestures, postures and intonation to amplify words, how to look natural on camera and to feel comfortable presenting." Related to this, Figure 2 shows an example of practicing interview-style presentations in front of a camera in one of our workshops. 


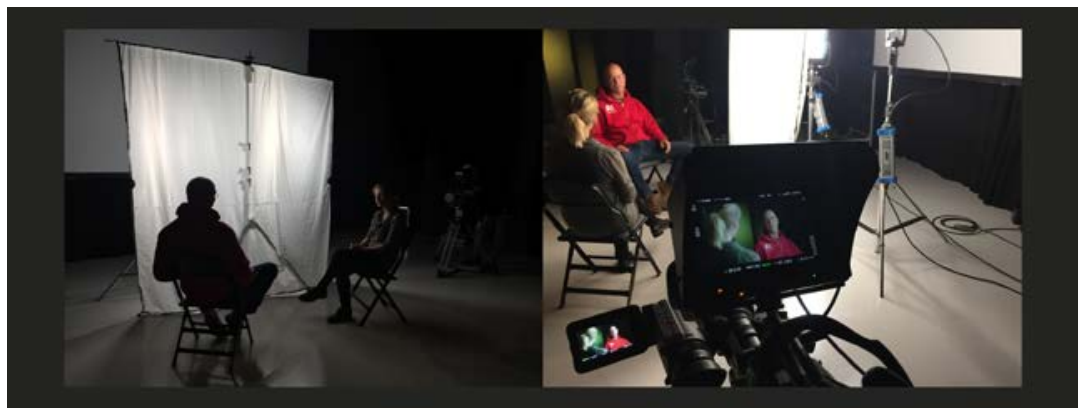

Figure 2. An example of an interview-style setting from our workshop to practice presentation skills.

Using a teleprompter. "In this session participants revise what a teleprompter is and how it works, why it is widely used in video production, then get a feel of it and try how it actually works with their own scripts. After this they move on to setting it up and the workshop is concluded by reflecting on the experience."

Using tablet as a whiteboard. "One way to make a video more interactive and easier to follow is to use a tablet as a whiteboard. It is especially important for those subjects where writing on a board is a must in general, like math or physics. Every participant gets a tablet to use as a whiteboard and can test how it works and how to record the whiteboard writings as a video.”

Using visual resources in videos. "In this workshop we discuss how teachers can use music, images, footages in their videos without violating copyrights. The guidelines on using creative commons materials are also given and creative common licenses are analyzed."

Creating animations for your videos. "Animations can help to carry a story and help learners to see the contents via visual examples. In this workshop we learn how to create animations with selected online tools, and to include them as a part of the educational videos.”

\section{Evaluation via feedback from the community and resulting categorization}

With our approach, teachers not only broaden their knowledge and develop new skills but also become a part of the community. Thus they can more easily share their experiences with like-minded people, learn from each other and exchange best practices. From a cognitive point of view, it is much safer to dive into a completely new domain when you know you have support from peers and you are not the only one on that unknown road.

After our activities we have received informal feedback from teachers saying that the environment has been encouraging and safe to practice. Teachers have appreciated the idea of learning by doing, and found workshops to be very insightful and intense. 
As a result of developing and evaluating the approach now for almost two years, we have distilled a production model for educational videos, consisting of four categories (see Figure 3). Thus we offer deliverables ranging from self-service studio quality through good quality fast all the way to videos of high production value and to top quality videos. After the teacher has gone through a number of workshops, we make a brief to the producer about a video (or a set of videos) for an online course, and select the best fitting production category.

The factors that influence the choice of the category are, for instance, presentation skills and experience of the teacher, the planned use of the video and timespan within which the video needs to be produced. Based on that, we offer a case setting for the teacher and the producer takes the project forward.

\begin{tabular}{|c|c|c|c|c|}
\hline \multirow[t]{2}{*}{ Deliverable } & Self-made quality & Good quality fast & $\begin{array}{l}\text { High production } \\
\text { value }\end{array}$ & Top-quality video \\
\hline & $\begin{array}{l}\text { Recording or } \\
\text { streaming a video in a } \\
\text { lecture room, or in a } \\
\text { self-service studio. } \\
\text { Tech assistant's help } \\
\text { is available. }\end{array}$ & $\begin{array}{l}\text { One teacher and one } \\
\text { cameraman in a } \\
\text { suitable space } \\
\text { (classroom, lobby, } \\
\text { outdoors, self- } \\
\text { service studio). }\end{array}$ & $\begin{array}{l}\text { 3-4 person crew } \\
\text { (cameraman, sound } \\
\text { designer, editor, } \\
\text { graphic designer) in a } \\
\text { pro studio, or other } \\
\text { suitable space. }\end{array}$ & $\begin{array}{l}10 \text { person crew, } \\
\text { director involved, a } \\
\text { compelling story, } \\
\text { pro studio and } \\
\text { setup. Global target } \\
\text { audience. }\end{array}$ \\
\hline Timespan & 2 days to 1 month & 5 days to 1 month & 2 weeks to 2 months & 3 to 6 months \\
\hline Persona & $\begin{array}{l}\text { Emil, wants to make } \\
\text { videos }\end{array}$ & $\begin{array}{l}\text { Sara, good } \\
\text { presentation skills }\end{array}$ & $\begin{array}{l}\text { Jack, good } \\
\text { presentation skills, } \\
\text { eager to learn }\end{array}$ & $\begin{array}{l}\text { Tina, experienced, } \\
\text { excellent } \\
\text { presentation skills }\end{array}$ \\
\hline
\end{tabular}

Figure 3. Production categories.

\section{Conclusions}

Educational videos can support moving from traditional teacher-centered settings to learner-centered settings. Flipped classroom methods, for instance, imply that students have checked the theory via online materials before entering the face-to-face sessions coached by the teacher in a classroom. However, making videos to be supporting learning remains a challenge: videos are simply a completely different medium than lecturing to an audience from a podium. Good postures, eye contact, talented use of voice and engaging storyline are obviously also present in lecturing, but can and should take quite different forms in front of 
the camera. In this paper we proposed a process to improve teacher's competencies for supporting them to prepare better educational videos. Our approach consists of a set of workshops on different aspects of video production, ranging from presentation skills and script writing to working with advanced techniques such as animations and use of teleprompters. We described a representative set of workshops we have used, and the four categories of different production types for educational videos, all having characteristics and personas helping to create a brief for the production.

\section{References}

Guo PJ, Kim J and Robin R (2014). How video production affects student engagement: An empirical study of MOOC videos. ACM Conference on Learning at Scale (L@S 2014)

Hsin WJ and Cigas J (2013). Short videos improve student learning in online education. Journal of Computing Sciences in Colleges 28, 253-259.

Kahneman D (2011). Thinking, Fast and Slow. Macmillan.

Kauppinen T and Malmi L (2017). Aalto Online Learning - a pathway to reforming education at the Aalto University. In Proceedings of EUNIS 23rd Annual Congress (EUNIS2017) - Shaping the Digital Future of Universities, pp. 212-221. Münster, Germany.

Lin S-Y, Aiken J, Seaton D, Douglas S, Greco E, D. Thoms B and F. Schatz M (2017). Exploring physics students' engagement with online instructional videos in an introductory mechanics course. Physical Review, Physics Education Research.

Seaton D, Nesterko S, Mullaney T, Reich J, Ho A and Chuang I (2014), Characterizing Video Use in the Catalogue of MITx MOOCs. In proceedings of European MOOC stakeholders summit. Lausanne, Switzerland. 